\title{
ENCONDROMATOSIS MÚLTIPLE: CASO CLÍNICO Y ACTUALIZACIÓN
}

Santiago Martínez-Torre ${ }^{1}$, María A. Molina-Medina ${ }^{1}$, Olga E. Tolentino-Ureña² e Inmaculada Gómez-Molinero ${ }^{1 *}$ 'Medicina de Familia, Centro de Salud Ciudad de los Periodistas, Hospital Universitario La Paz, Madrid, España; ${ }^{2}$ Facultad de Ciencias de la Salud, Pontificia Universidad Católica Madre y Maestra de los Caballeros, República Dominicana

RESUMEN: La encondromatosis múltiple se define por la presencia de múltiples tumores óseos de origen cartilaginosos (encondromas) con distribución asimétrica. La prevalencia estimada es de 1/100,000. Está incluida en el registro de enfermedades raras Orpha-net. La Organización Mundial de la Salud denomina síndrome de Ollier a esta patología. A continuación, presentamos un caso clínico de encondromatosis múltiple detectado y seguido en nuestra consulta de Atención Primaria, acompañado de las pruebas complementarias realizadas, el cual creemos es muy representativo de dicha entidad.

Palabras clave: Encondromatosis. Enfermedad de Ollier. Síndrome de Maffucci.

\section{MULTIPLE ENCHONDROMATOSIS: CLINICAL CASE AND UPDATE}

ABSTRACT: The multiple enchondromatosis is defined by the presence of multiple bone tumors of cartilaginous origin (enchondromas) with asymmetric distribution. The estimated prevalence is $1 / 100,000$. It is included in the register of rare diseases Orpha-net. This pathology is named $\mathrm{Ol}$ lier disease by the World Health Organization. We present a clinical case of multiple enchondromatosis detected and followed in our practice, accompanied by complementary tests, which we believe is very representative of that entity. (Rev Mex Med Fam. 2019;6:125-8)

Corresponding author: Inmaculada Gómez-Molinero, igomezmolinero@gmail.com

Key words: Enchondromatosis. Ollier disease. Maffucci syndrome.

\section{INTRODUCCIÓN}

La encondromatosis múltiple o enfermedad de Ollier se define por la presencia de múltiples tumores intraóseos de origen cartilaginoso llamados encondromas. Cuando la encondromatosis se asocia a hemangiomas de tejido blando se conoce como síndrome de Maffucci.

Está considerada como una enfermedad rara por su baja prevalencia $(1 / 100,000)$.

\section{Correspondencia:}

*Inmaculada Gómez-Molinero

E-mail: igomezmolinero@gmail.com
Las lesiones tumorales son benignas y su distribución asimétrica. Se desarrollan en puntos cercanos a la placa epifisaria de crecimiento del cartílago. Pueden ser muy variables en cuanto a tamaño, número, localización, evolución de los encondromas, edad de aparición y de diagnóstico y necesidad de cirugía.

Tanto la enfermedad de Ollier como el síndrome de Maffucci se presentan en casos aislados y no parecen depender de un solo 
gen o combinación de varias mutaciones (de la línea germinal o somática).

Su presentación clínica suele ser con dolor articular de tipo mecánico e impotencia funcional de las articulaciones afectadas. La repercusión clínica que provocan los encondromas, en los pacientes afectados, incluyen malformaciones esqueléticas, dismetría de extremidades y riesgo de malignización a condrosarcoma ${ }^{1}$.

El deterioro funcional y la discapacidad que pueden desarrollar estos pacientes afecta tanto a su vida familiar como a su trayectoria laboral.

El diagnóstico se basa en la clínica junto con la radiología convencional y se utilizan técnicas de imagen más avanzadas (resonancias magnéticas y gammagrafías óseas), así como estudio histológico ante la sospecha de malignidad.

No existe un tratamiento médico para la encondromatosis. La cirugía se recomienda solo en caso de complicaciones (fracturas patológicas, defectos de crecimiento y transformación maligna).

El pronóstico de la enfermedad es difícil de establecer. Las formas de presentación precoz suelen ser más graves. En la enfermedad de Ollier existe un riesgo de malignización a condrosarcoma en el 25-50\% de los casos según los estudios ${ }^{2}$.

\section{CASO CLÍNICO}

Paciente varón de 42 años, de profesión comercial y aficionado a tocar la batería, que consulta a su médico de Atención Primaria por dolor leve de tipo mecánico en rodilla derecha, de varios meses de evolución, que no le limita funcionalmente. El paciente lo relaciona con el sobresfuerzo típico de su profesión y sus aficiones. Refiere asimismo molestias inespecíficas ocasionales en rodilla contralateral.

Los antecedentes familiares recogidos en su historia clínica son de: abuela materna y madre con diabetes mellitus tipo 2, hipercolesterolemia e hipertensión arterial; padre con neoplasia maligna de próstata, colon y pulmón. El paciente no tiene hijos.

Entre sus antecedentes personales destacan: leve escoliosis adquirida, secundaria a una dismetría en miembros inferiores de alrededor de $1 \mathrm{~cm}$, espina bífida oculta $S 1$ y hernia discal L5-S1 que le provoca lumbociática bilateral recidivante desde hace más de cinco años.

En la exploración física de aparato locomotor se destaca postura vertebral escoliótica como único hallazgo. La inspección de ambas rodillas en bipedestación y decúbito indica que están bien alineadas, sin desviación de los ejes mecánicos lateral, medial, anterior y posterior; no hay tumefacciones, signos inflamatorios articulares ni puntos dolorosos a la palpación.

Se solicita radiografía de ambas rodillas (Figs. 1 y 2), y se observa en la rodilla izquierda lesiones ovaladas trabeculadas, bien delimitadas en metáfisis de fémur y tibia izquierdos, que adelgazan ligeramente la cortical ósea.

Con la sospecha de tumor óseo a filiar, el paciente se remite al Servicio de Traumatología y se realiza una resonancia magnética de rodilla, que informan con cambios de señal en la médula ósea de fémur, tibia y rótula, lo que puede estar en relación con infartos óseos, sin poder descartar que se trate de un tumor óseo primario o secundario.

Para completar el estudio se realiza una gammagrafía ósea que muestra elevación patológica de la actividad metabólica en la diáfisis de fémur y tibia izquierdos. Las imágenes (Fig. 3) son compatibles con la presencia de encondromatosis múltiple del miembro inferior izquierdo, y se confirma así el diagnóstico.

Con el diagnóstico de encondromatosis múltiple o enfermedad de Ollier se cita al paciente a consulta de Medicina de Familia para comunicar los resultados, explicar el desarrollo natural, el pronóstico y posibles complicaciones ortopédicas y neoplásicas de la enfermedad, así como su asociación a algunas enfermedades oncológicas como hepatocarcinoma, cáncer de páncreas y ovario y gliomas.

Negociamos con el paciente y sus familiares más cercanos una estrategia de seguimiento planificado anual para detectar precozmente posibles síntomas y signos de alarma que puedan ponernos en situación de solicitar nuevos estudios de imagen para diagnosticar las complicaciones descritas. 


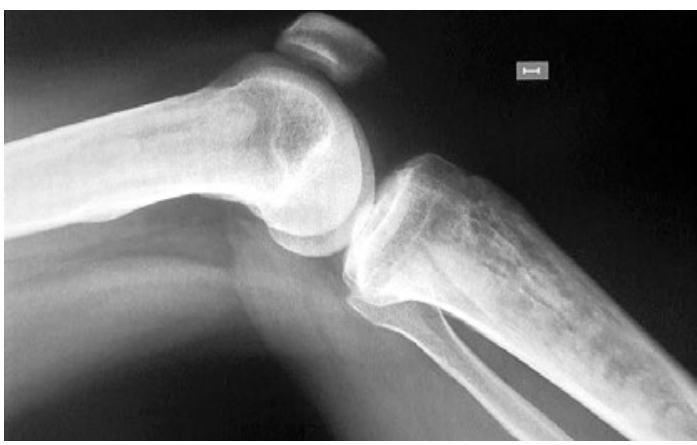

Figura 1. Radiografía simple lateral de rodilla.

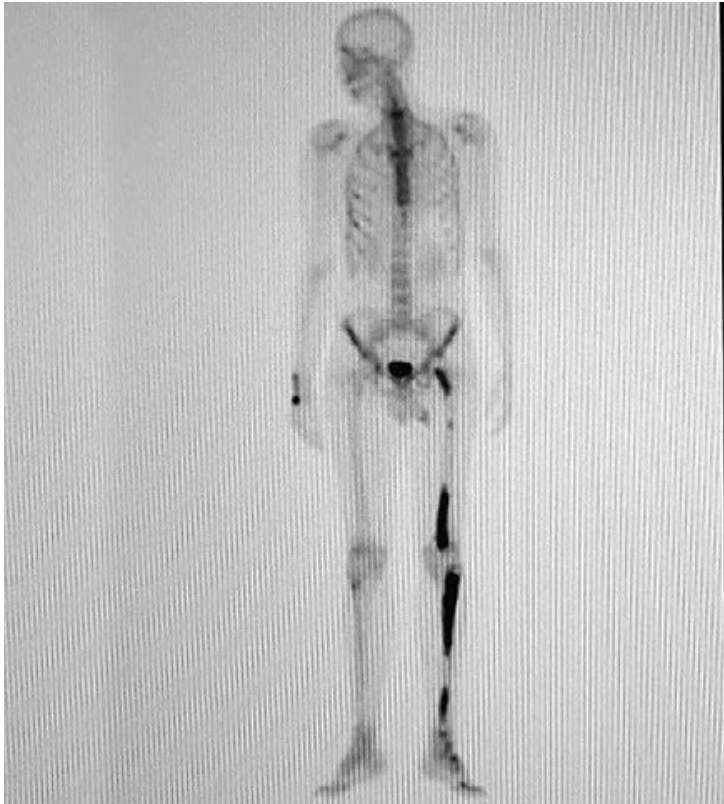

Figura 3. Gammagrafía ósea.

Implicamos al equipo de enfermería y fisioterapia para entrenar al paciente en técnicas de escuela de espalda y medidas higiénico-dietéticas de protección del aparato locomotor, evitando los hábitos tóxicos y el sobrepeso, y fomentando el ejercicio físico habitual.

\section{DISCUSIÓN Y EVIDENCIA CIENTÍFICA}

\section{Diagnóstico}

Por lo general, la mayoría de los pacientes con encondromatosis múltiple son diagnosticados de manera casual, como en el caso de nuestro paciente, con la aparición de un encondroma en pruebas de imagen convencionales como la radiografía simple. Esto nos obliga a descartar afectación de otros huesos realizando una gammagrafía ósea

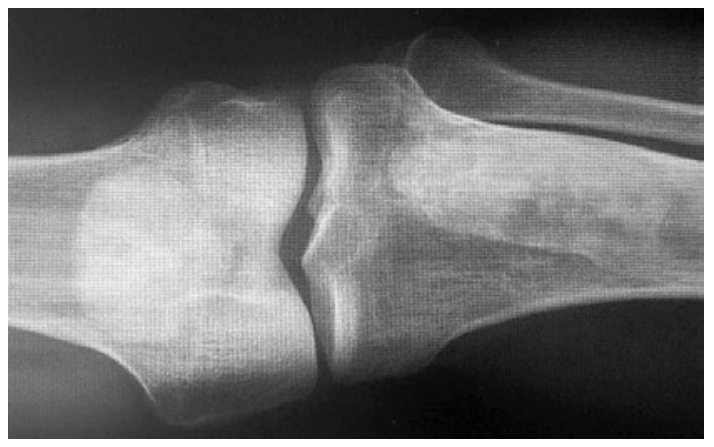

Figura 2. Radiografía simple anteroposterior de rodilla.

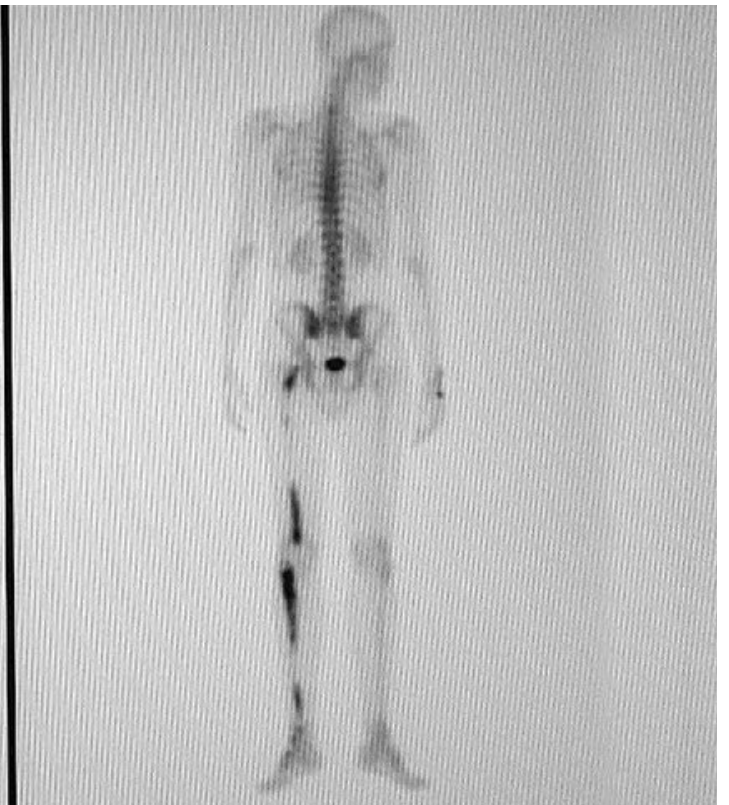
nos ante una enfermedad de Ollier o encondromatosis múltiple. En un menor grupo de pacientes el diagnóstico de la enfermedad se alcanza tras consultar por problemas de dismetría, deformidad ósea o dolor ${ }^{3}$.

La sospecha de malignización a condrosarcoma, sobre todo en la edad adulta, debe hacerse por el aumento de tamaño, el dolor continuo, la aparición de fracturas patológicas o los cambios en los métodos de imagen. Los síndromes de Maffucci y Ollier se asocian con relativa frecuencia a hepatocarcinoma, cáncer de páncreas, tumores de ovario y gliomas ${ }^{4}$.

Nuestro paciente ha sido asesorado por parte del equipo médico y de enfermería sobre los síntomas y signos de alarma que debe consultar para investigar posible malignización. 


\section{Diagnóstico diferencial}

El diagnóstico diferencial de los encondromas incluye los infartos óseos, los osteomas, los condromas periósticos, la displasia epifisiaria hemimélica y el condrosarcoma de bajo grado, sobre todo en aquellos pacientes con dolor en ausencia de fractura ${ }^{5}$.

En el caso que hemos presentado se realizaron pruebas de imagen como resonancia magnética y gammagrafía ósea para descartar otras entidades nosológicas.

\section{Localización}

Los encondromas suelen aparecer sobre todo en los huesos largos. La mitad de los casos (COmo el nuestro) presentan afectación de la extremidad inferior (fémur, seguido de la tibia, peroné y las falanges), la segunda localización más frecuente es la extremidad superior (humero, cúbito y radio) $)^{6}$. Aunque la presentación en la pelvis es poco habitual, la transformación maligna en esta localización es la más frecuente.

\section{Tratamiento}

Por lo general es una enfermedad benigna que no requiere tratamiento. Solo en aquellos casos sintomáticos que presentan dolor que no se controle con analgesia convencional, dismetrías o deformidad se puede plantear tratamiento quirúrgico con legrado e injerto óseo. Ante una malignización del encondroma a condrosarcoma el tratamiento es únicamente quirúrgico mediante resección amplia, ya que es un tumor que no responde a quimioterapia ni radioterapia ${ }^{7}$.

\section{Seguimiento desde Atención Primaria}

Como médicos de familia debemos favorecer el autocuidado del propio paciente desde el conocimiento de su enfermedad, y apoyar la rehabilitación funcional antes y después de la cirugía. Es de vital importancia la colaboración entre Atención Primaria y Especializada para monitorizar los cambios clínicos y así detectar precozmente síntomas de alerta (aumento de tamaño, dolor, etc.) que nos lleven a la detección temprana de las complicaciones potencialmente malignas.

\section{Pronóstico}

Al tratarse de una enfermedad de baja prevalencia considerada una enfermedad rara, es difícil estimar el riesgo de transformaciones malignas. Distintos estudios revelan que entre el 20 y el $50 \%$ de los pacientes pueden sufrir malignización de la enfermedad, siendo la edad media los 45 años. Las afectaciones extensas o las localizaciones en la pelvis tienen una mayor probabilidad de malignización y por tanto un peor pronóstico ${ }^{8}$.

\section{CONCLUSIONES}

La enfermedad de Ollier no es una patología frecuente que se atienda de forma habitual en Atención Primaria.

El médico de familia y el resto del equipo que atiende a personas con enfermedades crónicas tienen la obligación moral de actualizar sus conocimientos de forma permanente y así ofrecer a sus pacientes una buena atención y acompañamiento.

En este artículo hemos querido mostrar las posibilidades reales de un equipo de Atención Primaria en el manejo de enfermedades raras, con una puesta al día sobre la encondromatosis múltiple, y las estrategias de diagnóstico y seguimiento que podemos ofertar al paciente que la padece.

\section{CONFLICTO DE INTERESES}

Los autores declaran no tener ningún conflicto de interés.

\section{BIBLIOGRAFÍA}

1. Vázquez-García B, Valverde M., San-Julián M. Enfermedad de Ollier: tumores benignos con riesgo de malignización. Revisión de 17 casos B. An Pediatr (Barc). 2011;74(3):168-73.

2. Silve $C$, Jüppner H. Enfermedad de Ollier. Orphanet J Rare Dis. 2006;1:37.

3. Wenaden AE, Szyszko TA, Saifuddin A. Imágenes de reacciones periósticas asociadas con lesiones focales de hueso. Clin Radiol. 2005;60:439.

4. D’Angelo L, Massimi L, Narducci A, Di Rocco C. Ollier disease. Childs Nerv Syst. 2009;25:647-53.

5. Bovée JV. Multiple osteochondromas. Orphanet J Rare Dis. 2008;3:3.

6. Bierry G, Kerr DA, Nielsen GP, et al. Enchondromas en niños: aparición de imágenes con correlación patológica. Radiología es quelética. 2012;41:1223.

7. Carpintero P, del Fresno JA, Carpintero R, Gálvez MJ, Marín MA Complicaciones de los osteocondromas. Rev Esp Cir Osteoar. 2009;237:22-9.

8. Schwartz HS, Zimmerman NB, Simon MA. The malignant potential of enchondromatosis. J Bone Joint Surg Am. 1987;69:269-74. 